\title{
A Retrospective Study of Impact of PPTCT on HIV Trends, Maternal and Perinatal Outcome
}

\author{
Anjali Malhotra, Sumitra Yadav \\ MGMMC \& MYH, Indore, India \\ Email: anjalimalhotra.mbbs@gmail.com,drsumitrayadav@yahoo.co.in
}

How to cite this paper: Malhotra, A. and Yadav, S. (2016) A Retrospective Study of Impact of PPTCT on HIV Trends, Maternal and Perinatal Outcome. World Journal or AIDS, 6, 178-185.

http://dx.doi.org/10.4236/wja.2016.64020

Received: September 12, 2016

Accepted: November 29, 2016

Published: December 2, 2016

Copyright $\odot 2016$ by authors and Scientific Research Publishing Inc. This work is licensed under the Creative Commons Attribution International License (CC BY 4.0).

http://creativecommons.org/licenses/by/4.0/ (c) (i) Open Access

\begin{abstract}
Background: Women diagnosed with HIV/AIDS may transmit the infection to their child during pregnancy. The infection may spread during pregnancy, childbirth, or breastfeeding. However, the risk of mother-to-child transmission of HIV may be reduced by the use of HIV medications known as antiretroviral therapy (ART). Infection with HIV/AIDS is not a contraindication to pregnancy. Some women are unaware they have the disease until they become pregnant. In this case, they should begin antiretroviral therapy as soon as possible [1]. With the appropriate treatment, the risk of mother-to-child infection can be reduced to below 1\% [2]. Without treatment, the risk of transmission is $15 \%-45 \%$ [3]. Objective: The main aim of the study is to appreciate the declining trend of HIV in babies with HIV positive mother by implementation of PPTCT services. Methods: A retrospective study of detection of HIV positive mothers among all the antenatal patients attending OPD and including the patients coming in Emergency services and delivered in Department of Obstetrics and Gynecology at MGMMC \& M. Y. Hospital, Indore, Madhya Pradesh (India) from Jan 2006 to Dec 2015 was included in the study. They were screened for HIV status and further management of all HIV positive patients.
\end{abstract}

\section{Keywords}

Antiretroviral Therapy (ART), National AIDS Control Organization (NACO), Nevirapine (NVP), Prevention of Parent to Child Transmission (PPTCT)

\section{Introduction}

The human immunodeficiency virus (HIV) is a lentivirus (a subgroup of retrovirus) that causes HIV infection and over time acquired immunodeficiency syndrome (AIDS) [4] [5]. AIDS is a condition in humans in which progressive failure of the immune system allows life-threatening opportunistic infections and cancers to thrive. Without 
treatment, average survival time after infection with HIV is estimated to be 9 to 11 years, depending on the HIV subtype [6]. Infection with HIV occurs by the transfer of blood, semen, vaginal fluid, pre-ejaculate, or breast milk. Within these bodily fluids, HIV is present as both free virus particles and virus within infected immune cells.

HIV infects vital cells in the human immune system such as helper T cells (specifically CD4 + T cells), macrophages, and dendritic cells [7]. HIV infection leads to low levels of $\mathrm{CD} 4+\mathrm{T}$ cells through a number of mechanisms, including pyroptosis of abortively infected $\mathrm{T}$ cells [8], apoptosis of uninfected bystander cells [9], direct viral killing of infected cells, and killing of infected CD $4+\mathrm{T}$ cells by CD8 cytotoxic lymphocytes that recognize infected cells [10]. When $\mathrm{CD} 4+\mathrm{T}$ cell numbers decline below a critical level, cell-mediated immunity is lost, and the body becomes progressively more susceptible to opportunistic infections.

\section{Objectives}

- To take follow-up of those with HIV positive serology up to their delivery and their babies after delivery.

- To analyze the declining trend among HIV positive detected patients over a period of 10 years i.e. from Jan. 2009 to Dec. 2015.

- To appreciate the declining trend of HIV in babies with HIV positive mother by implementation of PPTCT services in MYH from Jan. 2009 to Dec. 2015.

- To detect rate of transmission according to method of delivery and treatment received during pregnancy.

\section{Materials and Method}

A retrospective study of detection of HIV positive among all the antenatal patients attending OPD and including the patients coming in Emergency services and delivered in Department of Obstetrics and Gynecology at MGMMC \& M. Y. Hospital, Indore, Madhya Pradesh (India) from Jan. 2009 to Dec. 2015 were included in the study. They were screened for HIV status and further management for all HIV positive patients.

\section{Results}

The incidence of HIV has dropped consistently i.e. from $1.4 \%$ in 2006 to $0.11 \%$ in 2015 as in Table 1 and Figure 1, representing the TESTED patients. The number of HIV positive patients being diagnosed among Antenatal OPD has consistently dropped from $0.5 \%$ in 2006 to $0.15 \%$ in 2015 . As evident from the data, the HIV positive mothers being diagnosed HIV positive has considerably dropped. The percentage of deliveries of People With HIV Positive has been in a consistent range from $0.5 \%$ in 2009 to $0.5 \%$ in 2012 to $0.4 \%$ in 2015 over the given time period of 7 years as in Table 2 and Figure 2. There is hike in rate of vaginal deliveries $(36.8 \%$ in 2009 to $71 \%$ in 2015) w.r.t decline in LSCS (63.1\% in 2009 to $29 \%$ in 2015) as in Table 3 and Figure 3. Babies undergoing LSCS had higher rate of Transmission w.r.t Vaginal 
Table 1. Comparison between different years and the declining trend of HIV positive cases as evident from the data over ten years.

\begin{tabular}{ccccc}
\hline Year & Total antenatal OPD & $\begin{array}{c}\text { Pre-test } \\
\text { counselled }\end{array}$ & $\begin{array}{c}\text { Tested (ANC }+ \\
\text { emergency) }\end{array}$ & HIV reactive \\
\hline 2006 & 6422 & 4261 & 2122 & 31 \\
2007 & 7055 & 5130 & 3888 & 32 \\
2008 & 7600 & 5839 & 4691 & 31 \\
2009 & 7693 & 6724 & 6194 & 29 \\
2010 & 9138 & 8479 & 6099 & 29 \\
2011 & 7594 & 7288 & 6594 & 35 \\
2012 & 7884 & 6672 & 9797 & 21 \\
2013 & 9481 & 7288 & 10,494 & 25 \\
2014 & 11,314 & 8843 & 17,363 & 35 \\
2015 & 9935 & 9960 & 13,274 & 15 \\
\hline
\end{tabular}

Table 2. HIV positive cases delivered in MYH.

\begin{tabular}{cccc}
\hline Year & Total deliveries & HIV positive cases & Percentage (in \%) \\
\hline 2009 & 9335 & 38 & 0.4 \\
2010 & 11,216 & 38 & 0.33 \\
2011 & 9847 & 50 & 0.50 \\
2012 & 10,226 & 60 & 0.58 \\
2013 & 9000 & 46 & 0.51 \\
2014 & 10,366 & 58 & 0.56 \\
2015 & 10,835 & 46 & 0.42 \\
\hline
\end{tabular}

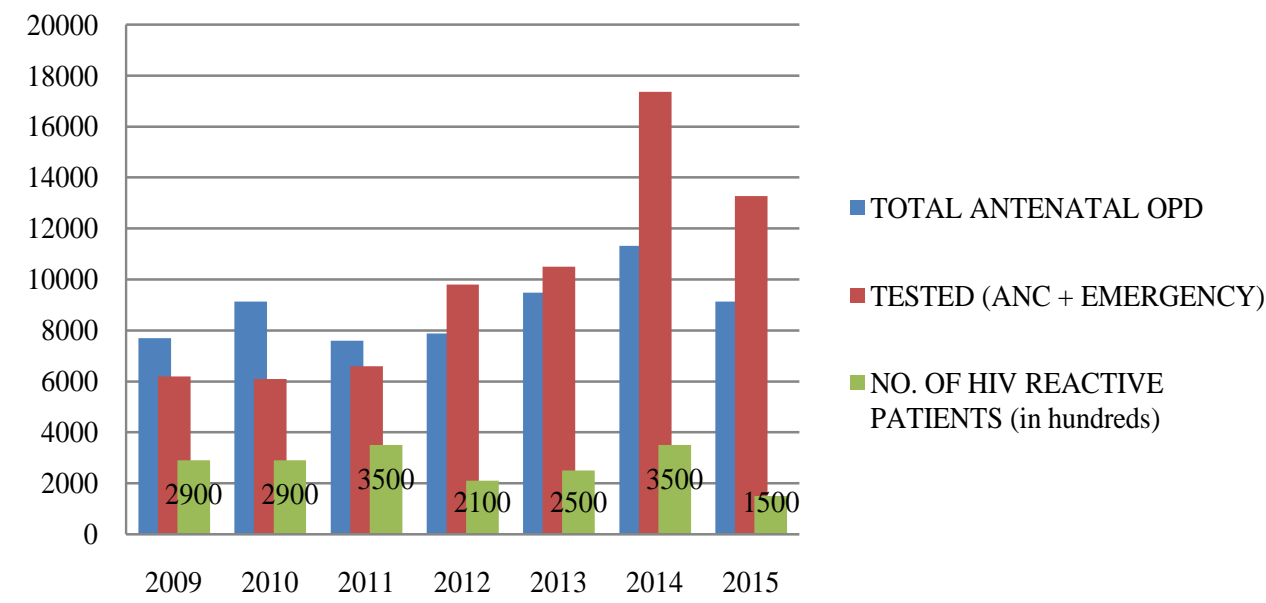

Figure 1. The declining trend of HIV positive cases as evident from the data over ten years and the no. of patients found to be HIV reactive. $x$ axis represents time (in years); $y$ axis represents number of patients. 


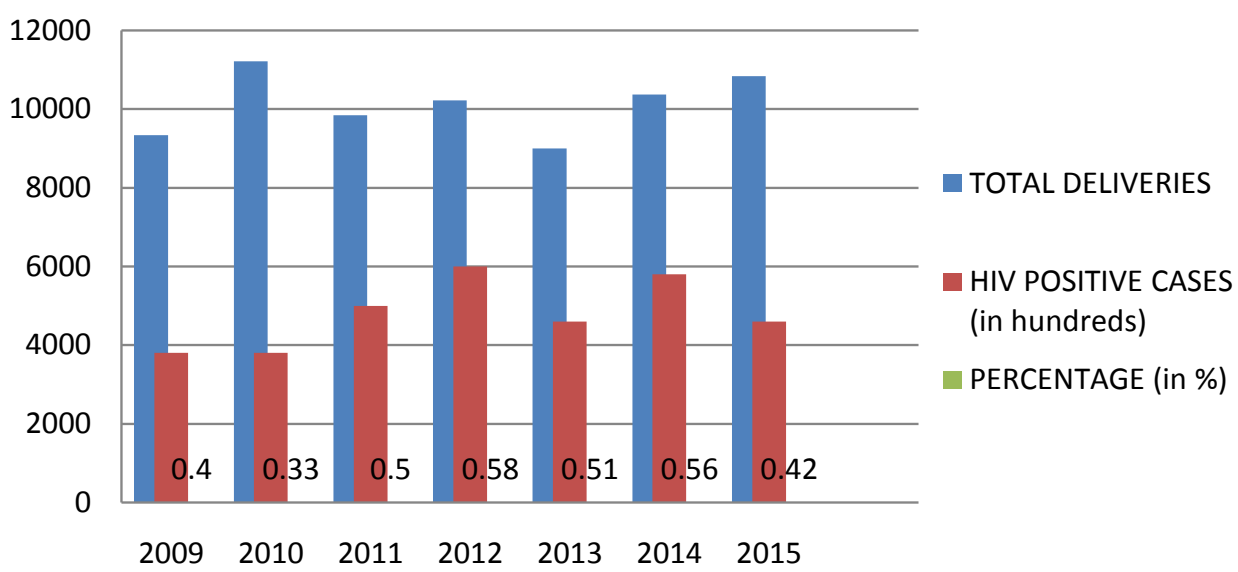

Figure 2. HIV positive cases delivered in MYH. $\mathrm{x}$ axis represents time (in years); $\mathrm{y}$ axis represents number of patients.

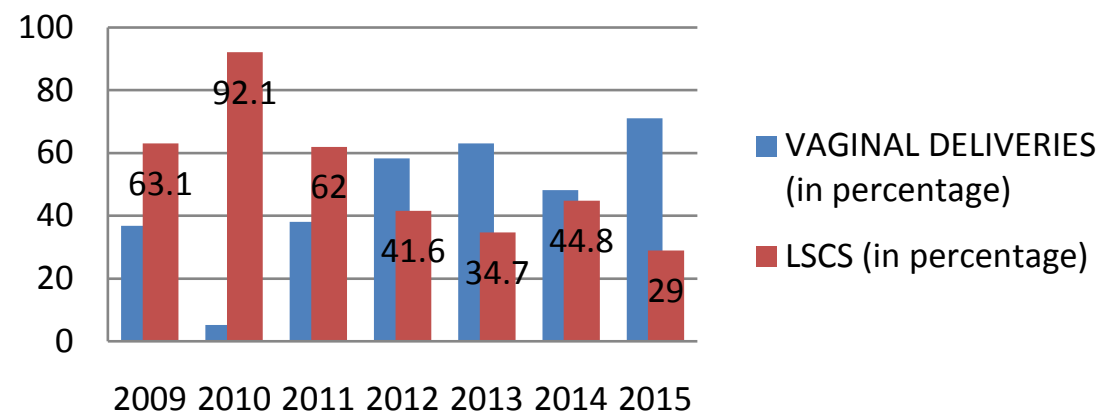

Figure 3. Mode of delivery in HIV reactive patients. $\mathrm{x}$ axis represents time (in years); $\mathrm{y}$ axis represents number of patients.

Table 3. Mode of delivery in HIV reactive patients.

\begin{tabular}{ccc}
\hline Year & Vaginal deliveries (in percentage) & LSCS (in percentage) \\
\hline 2009 & 36.8 & 63.1 \\
2010 & 5.2 & 92.1 \\
2011 & 38 & 62 \\
2012 & 58.3 & 41.6 \\
2013 & 63 & 34.7 \\
2014 & 48.2 & 44.8 \\
2015 & 71 & 29 \\
\hline
\end{tabular}

Deliveries. According to recent guideline, Elective LSCS is not recommended. It is evident from the data in Table 4 and Figure 4 that mother to child transmission was nearly 4 cases in LSCS and nearly 3 cases in VAGINAL deliveries in past 7 years. In Table 3 and Figure 5 in 2015, mostly vaginal deliveries were preferred i.e. 71\% w.r.t $36.8 \%$ in 2009. 
Table 4. Rate of transmission based on mode of delivery.

\begin{tabular}{ccccc}
\hline Year & Total vaginal deliveries & $\begin{array}{c}\text { Reactive babies in } \\
\text { vaginal deliveries }\end{array}$ & Total LSCS & $\begin{array}{c}\text { Reactive babies } \\
\text { in LSCS }\end{array}$ \\
\hline 2009 & 14 & 0 & 24 & 0 \\
2010 & 2 & 0 & 35 & 1 \\
2011 & 19 & 1 & 31 & 0 \\
2012 & 35 & 1 & 25 & 2 \\
2013 & 29 & 1 & 16 & 1 \\
2014 & 27 & 0 & 29 & 0 \\
2015 & 33 & 0 & 13 & 0 \\
\hline
\end{tabular}

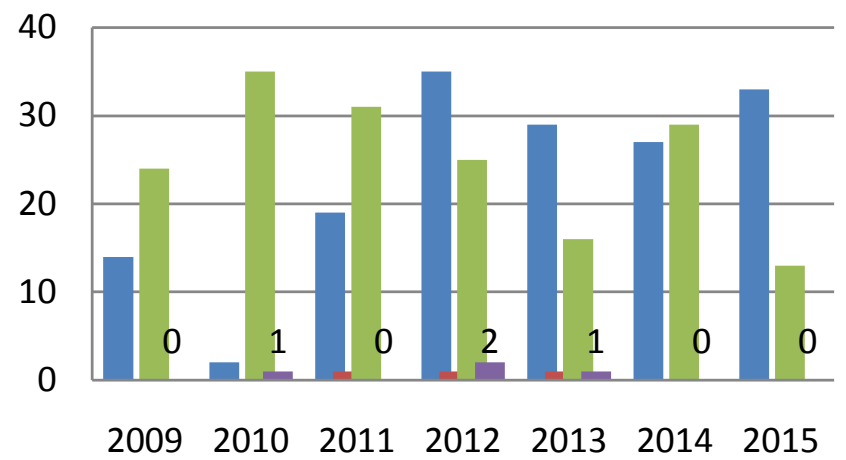

TOTAL VAGINAL

DELIVERIES

REACTIVE BABIES IN

VAGINAL DELIVERIES

TOTAL LSCS

REACTIVE BABIES IN LSCS

Figure 4. Rate of transmission based on mode of delivery. $\mathrm{x}$ axis represents time (in years); $\mathrm{y}$ axis represents number of patients.

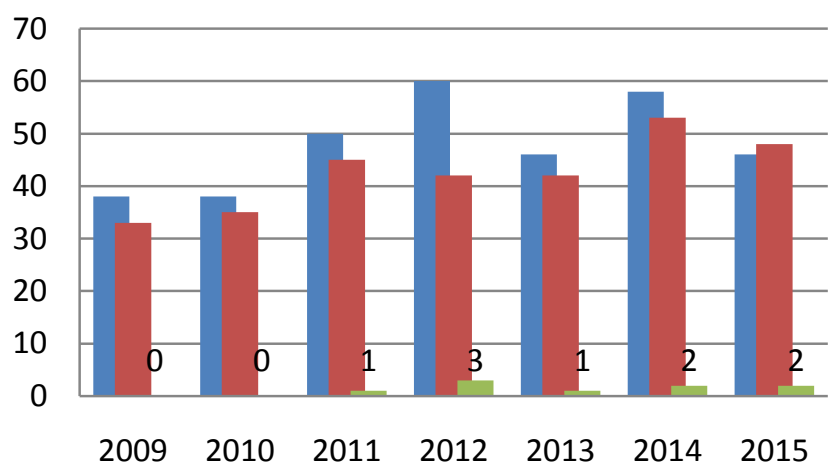

TOTAL NUMBER OF DELIVERIES

ALIVE HEALTHY BABIES

- INTRAUTERINE DEATH

Figure 5. Perinatal morbidity and mortality. $\mathrm{x}$ axis represents time (in years); $\mathrm{y}$ axis represents number of patients.

In accordance to NACO and PPTCT, Tablet NVP $200 \mathrm{mg}$ should be given 2 hours before planned delivery or at onset of labour. The newborn should be given nevirapine suspension. Now it has been changed to TLE Regimen to mother for atleast 24 weeks \& NVP to baby. According to recent guideline, Elective LSCS is not recommended. Mixed feeding should be avoided. Only Breast feeding should be continued in developing countries. None of the babies were found to HIV reactive at the end previous 2 years irrespective of mode of delivery as in Table 5 and Figure 5. 
Table 5. Perinatal morbidity and mortality.

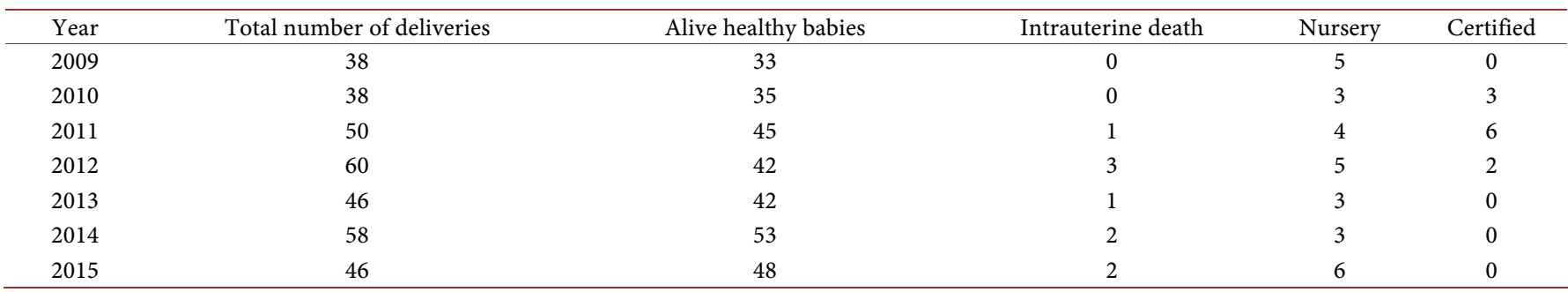

\section{Observations}

It was because of novel approach of NACP and PPTCT counselling enabling the antenatal women to be diagnosed earlier. In 2009 only 29 patients were found to be reactive w.r.t 2015 there were 15 patients who were reactive at our institute.

Most of the patients are getting delivered at a tertiary care center (MYH), thus ensuring the Prophylactic and Postnatal care of the mother and baby.

\section{Discussion}

The risk of vertical transmission of HIV from mother to baby ranges from $7 \%-40 \%$. Maternal HIV transmission is the primary means by which infant become infected. Hence prevention of maternal HIV transmission is of paramount importance. The Indian Council of Medical Research initiated a serosurveillance among high risk group to ascertain the magnitude of HIV infection at regular intervals so as to know the trends and patterns of the disease in the community which would facilitate proper prevention and management.

The study was conducted on all the HIV positive antenatal patients attending OPD and including the patients coming in Emergency services and delivered in Department of Obstetrics and Gynecology at MGMMC \& M.Y. Hospital, Indore, Madhya Pradesh (India) from Jan 2006 to Jan 2016. During this study period, there were 338 deliveries in these 7 years from Jan 2009 to Dec 2015. The most common route of infection is sexual transmission more commonly through male to female w.r.t female to male. So the fetus becomes the innocent bearer of the disease. These children were called at 6weeks, 6 months and 18 months for follow up.

The PPTCT program has significantly improvised its ANC OPD burden from 6422 in 2006, 9138 in 2010 to 9935 in 2015 among those for HIV screening as in Table 1. Out of them total of 2122 were tested in 2006 and 6099 in 2010 and 13,274 in 2015. It implies the efficacy of effective implementation of PPTCT program. From the data obtained, the incidence of HIV has dropped consistently i.e. from $0.5 \%$ to $0.15 \%$ i.e. from 2006 to 2015. Earlier LSCS was promoted for delivery in case of HIV positive patients but Now-a-days Elective LSCS has been implemented thus decreasing rate of transmission.

According to Kesho Bora study, Infants of mothers with undetectable virus levels after being given Triple ARVs at time of delivery has only $2.7 \%$ risk of HIV infection at the end of one year. So initiation of ARVs early in pregnancy and to all women who 
require ART irrespective of CD4 count as per 2013 guidelines significantly eliminate risk of Mother to Child HIV Transmission.

There were 338 deliveries from 2009 to 2015, 298 babies were found to be alive healthy and 11 were certified.29 went to nursery and 9 were with Intrauterine fetal demise.

\section{Conclusions}

- In accordance to NACO and PPTCT, Tablet NVP $200 \mathrm{mg}$ should be given 2 hours before planned delivery or at onset of labour. The newborn should be given Nevirapine suspension. Now, it has been changed to TLE Regimen to mother for at least 24 weeks \& NVP to baby.

- For preventing MTCT, Triple ART should be started irrespective of CD4 count and clinical stage.

The 2010 revised PMTCT guidelines refer to the following two key approaches:

1) Lifelong ART for HIV-infected women in need of treatment for their own health, which is also safe and effective in reducing mother to child transmission of HIV (MTCT).

2) Short-term ARV prophylaxis to prevent MTCT during pregnancy, delivery and breastfeeding for HIV-infected women not in need of treatment.

Eligibility for treatment:

- The 2006 guidelines recommended starting lifelong ART for pregnant women with a CD4 count equal to or below 200 cells $/ \mathrm{mm}^{3}$, usually the stage at which the immune system is no longer strong enough to prevent opportunistic diseases.

- The 2010 guidelines promote starting lifelong ART for all pregnant women with severe or advanced clinical disease (stage 3 or 4), or with a CD4 count at or below 350 cells $/ \mathrm{mm}^{3}$, regardless of symptoms. The new ART eligibility criteria, which are the same as those for adults in general, emphasize the need for access to CD4 testing.

- Both the previous and new PMTCT ARV guidelines recommend that HIV positive pregnant women in need of treatment for their own health should start ART irrespective of gestational age and should continue with it throughout pregnancy, delivery, during breastfeeding and thereafter.

- In both sets of guidelines, the timing of ART initiation for HIV-positive pregnant women is the same as for non-pregnant women, i.e. as soon as the eligibility criteria are met. Women are the same as for non-pregnant women, i.e. as soon as the eligibility criteria are met [11].

- Following guidelines can prevent Parent to Child transmission.

\begin{tabular}{cc}
\hline Category & Treatment duration \\
\hline All pregnant women presenting late in labour and breast feeding & Triple ART for 24 weeks \\
NVP to baby when mother on ART since diagnosed & For 6 weeks \\
NVP to baby when mother was started on ART in late pregnancy, during or after delivery & For 12 weeks \\
Infants of breast feeding babies not exclusive feeding & Give NVP \\
\hline
\end{tabular}




\section{References}

[1] HIV and Pregnancy, Fact Sheet from http://aidsinfo.nih.gov/. Reviewed August 2015. Developed by the US Department of Health and Human Services (HHS) Panel on Treatment of HIV-Infected Pregnant Women and Prevention of Perinatal Transmission, a Working Group of the Office of AIDS Research Advisory Council (OARAC).

[2] Coutsoudis, A., Kwaan, L. and Thomson, M (2010) Prevention of Vertical Transmission of HIV-1 in Resource-Limited Settings. Expert Review of Anti-Infective Therapy, 8, 11631175. https:/doi.org/10.1586/eri.10.94

[3] World Health Organization (2015) Mother-to-Child Transmission of HIV. World Health Organization, Geneva.

[4] Weiss, R.A. (1993) How Does HIV Cause AIDS? Science, 260, 1273-1279. https:/doi.org/10.1126/science.8493571

[5] Douek, D.C., Roederer, M. and Koup, R.A. (2009) Emerging Concepts in the Immunopathogenesis of AIDS. Annual Review of Medicine, 60, 471-484.

https:/doi.org/10.1146/annurev.med.60.041807.123549

[6] UNAIDS, WHO (2007) 2007 AIDS Epidemic Update. 10. UNAIDS, WHO, Geneva.

[7] Cunningham, A.L., Donaghy, H., Harman, A.N., Kim, M. and Turville, S.G. (2010) Manipulation of Dendritic Cell Function by Viruses. Current Opinion in Microbiology, 13, 524529. https:/doi.org/10.1016/j.mib.2010.06.002

[8] Doitsh, G., Galloway, N.L.K., Geng, X., Yang, Z.Y., Monroe, K.M., Zepeda, O., Hunt, P.W., Hatano, H., Sowinski, S., Muñoz-Arias, I. and Greene, W.C. (2014) Cell Death by Pyroptosis Drives CD4 T-Cell Depletion in HIV-1 Infection. Nature, 505, 509-514. https:/doi.org/10.1038/nature12940

[9] Garg, H., Mohl, J. and Joshi, A. (2012) HIV-1 Induced Bystander Apoptosis. Viruses, 4, 3020-3043. https:/doi.org/10.3390/v4113020

[10] Kumar, V. (2012) Robbins Basic Pathology. 9th Edition, 147.

[11] http://www.who.int/hiv/pub/mtct/PMTCTfactsheet/en/

\section{Submit or recommend next manuscript to SCIRP and we will provide best service} for you:

Accepting pre-submission inquiries through Email, Facebook, LinkedIn, Twitter, etc. A wide selection of journals (inclusive of 9 subjects, more than 200 journals)

Providing 24-hour high-quality service

User-friendly online submission system

Fair and swift peer-review system

Efficient typesetting and proofreading procedure

Display of the result of downloads and visits, as well as the number of cited articles

Maximum dissemination of your research work

Submit your manuscript at: http://papersubmission.scirp.org/

Or contactwja@scirp.org 